\title{
A preservação da memória da saúde na gestão documental dos arquivos hospitalares ${ }^{i}$
}

Rosane Oliveira Ramosii

\begin{abstract}
RESUMO:
Os hospitais são organizações prestadoras de serviços de assistência em saúde e produzem documentos relacionados às suas atividades meio e fim. Ao fim de seu valor de utilização primário, os documentos que alcançam valor histórico, são custodiados pelos arquivos permanentes de acordo com a política de gestão documental e a legislação vigente. Este estudo objetiva analisar o papel da gestão documental na preservação da memória da saúde nos documentos dos arquivos hospitalares. Utiliza o método de revisão de literatura, através de pesquisa em livros, artigos e sites. Descreve as características gerais das organizações hospitalares. Conceitua os documentos e o seu valor primário e secundário. Analisa a importância do prontuário do paciente para a memória da saúde. Identifica o papel dos arquivos hospitalares como instituições de memória. Constata a importância da gestão e das ações de preservação documental para a preservação e acesso à memória social da saúde.
\end{abstract}

Palavras-chave: Arquivo hospitalares. Documentação hospitalar. Gestão documental. Memória social da saúde.

\section{The preservation of health memory in the document management of the hospital archives}

\begin{abstract}
:
Hospitals are organizations providing health care services and produce documents related to their middle and end activities. At the end of their primary use value, documents that adjust historical value are guarded by permanent archive in accordance with a document management policy and current legislation. This study aims to analyze the role of document management in the preservation of health memory in hospital records. It uses the method of literature review, through research in books, articles and websites. Describes the general characteristics of hospital organizations. Conceptualize the documents and their primary and secondary value. It analyzes the importance of the patient's medical record to health caring system memory. It identifies the role of hospital archives as memory institutions. It notes the evaluation of management and document preservation actions for the preservation and access to social memory of health.
\end{abstract}

Keywords: Hospital files. Hospital documentation. Document management. Social memory of health caring system.

Data de submissão: 27/02/2018 - Data de aprovação: 05/06/2018

\footnotetext{
i Artigo apresentado originalmente como trabalho de conclusão do Curso de Esp. em Gestão Documental do Depart. de Ciência da Informação da Universidade Federal do Rio Grande do Norte.

ii Graduada em Biblioteconomia e especialista em Gestão Documental do Departamento de Ciência da Informação da Universidade Federal do Rio Grande do Norte no primeiro semestre de 2017.
} 


\section{INTRODUÇÃO}

Os hospitais são organizações complexas que desenvolvem atividades direcionadas para assistência em saúde, assumindo diferentes configurações em sua estrutura organizacional, serviços, equipes, equipamentos, processos e procedimentos de acordo com seus objetivos e nível de atuação.

O Manual Técnico do Cadastro Nacional de Estabelecimentos de Saúde Versão 2 (BRASIL, 2006), do Ministério da Saúde, classifica os hospitais quanto ao tipo de estabelecimento em: hospital geral, destinado à prestação de atendimento nas especialidades básicas por especialistas e/ou outras especialidades médicas; hospital especializado, destinado à prestação de assistência à saúde em uma única especialidade/área e hospital dia - isolado, unidade especializada no atendimento de curta duração com caráter intermediário entre a assistência ambulatorial e a internação.

Nestas organizações, as atividades assistenciais variam de acordo com o tipo de hospital, porte, nível de complexidade de sua atuação, âmbito público ou privado, variando as categorias profissionais e os departamentos de cada instituição.

De uma forma geral, trabalham nos hospitais profissionais das diversas especialidades médicas, enfermeiros e técnicos de enfermagem, nutricionistas, farmacêuticos, equipe de reabilitação (fisioterapeutas, fonoaudiólogos e terapeutas ocupacionais), psicólogos, assistentes sociais, agentes técnicos administrativos, agentes de serviços gerais entre outros.

Com estrutura organizacional em geral hierárquica e departamentalizada, do nível estratégico ao operacional, as organizações hospitalares são estruturadas em função de suas atividades meio e fim. Nessas atividades, diversas espécies documentais são criadas em razão das funções meio (atividades de ordem administrativa) e fim (atividades assistenciais em saúde).

Para a realização de suas atividades-meio, os hospitais contam com departamentos de gestão administrativa como: divisão de finanças, de gestão de pessoal, de materiais e de serviços gerais. Como atividades de apoio: central de esterilização de materiais, lavanderia, serviço de manutenção, Serviço de Arquivo Médico e Estatística (SAME), farmácia, entre outros.

Pertinente à atividade fim hospitalar, o prontuário do paciente é um conjunto documental com os registros de todos os procedimentos realizados pelos profissionais 
na atividade assistencial hospitalar a um determinado paciente por um determinado período.

Custodiados pelos arquivos hospitalares, os prontuários se constituem em fontes de informação de valor primário e secundário. No tocante ao valor secundário (histórico) o prontuário dos pacientes e os arquivos representam parte da memória da saúde, que para poder ser acessada precisa ser gerenciada e preservada.

Este artigo tem como objetivo o estudo do papel da gestão documental dos arquivos hospitalares com relação à preservação da memória na saúde.

A metodologia adotada para a pesquisa foi a revisão de literatura em livros, artigos e websites para fundamentar os conceitos e características de organizações hospitalares, documentação hospitalar, arquivo hospitalar, gestão e preservação documental, articulando esses estudos com reflexões sobre a questão da preservação da memória.

Para tanto, esta pesquisa teve como propósito se consolidar como um projeto inicial para futuros aprofundamentos teóricos e pesquisas de campo abrangendo a temática da gestão documental na preservação da memória na área de saúde.

Como objeto de estudo na Ciência da Informação, a gestão documental é um campo de pesquisa diretamente relacionado à área arquivística em interdisciplinaridade com outros conhecimentos, como os da área administrativa em gestão documental nas organizações, que alcança uma ampliação do seu escopo científico e social, no contexto do valor histórico dos documentos.

As informações documentais dos arquivos hospitalares testemunham as práticas em saúde com potencial de interesse para pesquisadores e para a sociedade pelo seu valor de representação de identidade social, o que demonstra a relevância de estudos sobre a preservação da documentação armazenada nos arquivos permanentes de instituições hospitalares.

\section{DOCUMENTAÇÃO HOSPITALAR}

Dentre os conceitos de documento, de forma genérica, "documento é qualquer elemento gráfico, iconográfico, plástico ou fônico pelo qual o homem se expressa" (BELLOTTO, 2006, p. 35). Essa afirmação já demonstra a amplitude conceitual do termo, que além das citadas, abrange todas as formas de registro, incluindo as eletrônicas e digitais produzidas em decorrência das atividades humanas. 
A abrangência do universo documental é considerada por Schellenberg (2006, p. 41), ao definir documento como:

Todos os livros, papéis, mapas, fotografias ou outras espécies documentárias, independentemente de sua apresentação física ou características, expedidos ou recebidos por qualquer entidade pública ou privada no exercício de seus encargos legais ou em função das suas atividades e preservados ou depositados para preservação por aquela entidade ou por seus legítimos sucessores como prova de suas funções, sua política, decisões, métodos, operações ou outras atividades, ou em virtude do valor informativo dos dados neles contidos.

Como em todas as organizações complexas, nos hospitais uma grande massa documental relacionada às suas atividades são produzidas, recebidas e tramitadas pelos setores internos até sua destinação final em arquivos institucionais, unidades de informação e documentação hospitalar, encarregados da gestão de todo o volume documental. "Esses documentos são, na realidade, os mesmos de que se valerão os historiadores, posteriormente, para recolherem dados referentes ao passado, já no recinto dos arquivos permanentes" (BELLOTTO, 2006, p. 23).

O prontuário do paciente é um dossiê que contêm informações desde seu registro de admissão até sua baixa por alta, óbito ou transferência para outra unidade hospitalar.

Devido a sua importância administrativa, jurídica e informativa, o prontuário médico é regulamentado pela resolução 1.638/2002, do Conselho Federal de Medicina (CFM) que em seu Art 1ํㅡ, define prontuário do paciente como:

[...] o documento único constituído de um conjunto de informações, sinais e imagens registradas, geradas a partir de fatos, acontecimentos e situações sobre a saúde do paciente e a assistência a ele prestada, de caráter legal, sigiloso e científico, que possibilita a comunicação entre membros da equipe multiprofissional e a continuidade da assistência prestada ao indivíduo.

A essa dimensão jurídica, ética, assistencial e informativa, soma-se a científica e social a partir da possibilidade das informações serem acessadas por pesquisadores interessados na investigação das práticas, técnicas e avanços científicos em saúde, assim como os estudos demográficos e epidemiológicos que interessam principalmente as pesquisas em saúde pública.

Nesta perspectiva, os registros de informação relacionados à saúde, custodiados pelos arquivos hospitalares, representam valiosa fonte de informação sobre a memória da saúde. 


\subsection{Valor dos documentos arquivísticos}

Nas instituições, os documentos são criados e utilizados até esgotar-se o seu valor primário, que de acordo com Bellotto (2006) apresentam valor para os fins explícitos aos quais foram criados, enquanto os de valor secundário são os que, cumpridos os objetivos para a sua criação, assumem valor histórico.

Se para os documentos de valor primário as instituições reconhecem o valor de desenvolvimento referente a seus processos e atividades meio e fim, para os documentos de valor histórico é necessário a ampliação do olhar na valoração e compreensão da importância de um documento; um olhar social que reflete a compreensão do lugar da memória como bem cultural e como resposta para a compreensão de questões futuras, pois, "ultrapassado o seu uso primário, iniciam-se os usos científico, social e cultural dos documentos" (BELLOTO, 2006, p. 24).

Nos arquivos hospitalares, os documentos de valor secundário têm potencial para informar e produzir conhecimento sobre as práticas assistenciais, a organização administrativa das instituições de saúde, o contexto social das políticas de saúde, dados epidemiológicos, avanços científicos, agentes de saúde, enfim, sobre uma amplitude de aspectos e temas relacionados a informações no que concerne à gestão, promoção e assistência à saúde. Os documentos também testemunham a história das práticas arquivísticas em arquivos hospitalares ao longo dos tempos.

\section{ARQUIVOS HOSPITALARES: INSTITUIÇÕES DE MEMÓRIA}

Os arquivos hospitalares são em geral denominados arquivos médicos. Porém, o termo arquivo hospitalar parece mais apropriado para essas unidades de informação, visto que nos hospitais os documentos são produzidos por equipe multidisciplinar. O Manual Técnico do Cadastro Nacional de Estabelecimentos de Saúde (BRASIL, 2006) define Unidade de Documentação e informação como:

Unidade destinada à identificação, seleção, controle, guarda, conservação e processamento das informações de todos os dados clínicos e sociais de paciente ambulatorial ou internado. Compreende o registro geral, o arquivo médico e estatística.

Esses arquivos são classificados como especializados, considerados unidades de apoio ao serviço hospitalar, em geral vinculado ao Serviço de Arquivo Médico e Estatística (SAME), assumindo diferentes configurações na sua localização 
na estrutura organizacional da instituição hospitalar. O SAME é um serviço responsável pela identificação dos pacientes e pela manutenção dos prontuários de forma acessível e ordenada, de acordo com os critérios estabelecidos pela organização hospitalar (CRUZ, 2015).

De acordo com Barreto (2007, p. 162), o processo do conhecimento:

[...] se dá através da mediação da informação. Esse papel fica a cargo das instituições de memória, de seus profissionais que, com seus instrumentos de armazenagem, processamento e disseminação da informação organizam e permitem sua difusão em variados modos: textos, imagens, sons, meios que traçam signos e abrem vias para a passagem do conhecimento, organizando sua materialidade.

Os arquivos permanentes de organizações hospitalares preenchem os requisitos de instituições de memória em acervos de origem orgânica em saúde.

\section{GESTÃO DOCUMENTAL DE ARQUIVOS PERMANENTES}

A evocação do passado através de fontes documentais só é possível mediante uma política de Gestão Documental (GD) que fundamente, normalize e oriente as tomadas de decisões relativas à classificação, avaliação e preservação da documentação orgânica, desde a produção documental até a sua guarda permanente. "A operação denominada recolhimento conduz os papéis a um local de preservação definitiva: os arquivos permanentes" (BELLOTTO, 2006, p. 24).

As mudanças na demanda social por informações impulsionadas pelo desenvolvimento científico, técnico e cultural ao longo dos tempos determinaram modificações na organização das instituições de guarda documental, influenciando na evolução de técnicas e metodologias com fins de atender às novas relações entre as instituições e o público atendido.

$\mathrm{Na}$ antiguidade o conceito de arquivo estava diretamente relacionado ao aspecto legal dos documentos. No início do século XIX, houve um crescente interesse pelo valor histórico dos documentos de arquivo. Em meados do século XX, após a II Guerra Mundial, o progresso científico e tecnológico acarretou a produção de grandes massas documentais. Nesse ambiente surgiu a teoria das três idades dos arquivos (PAES, 2004).

De acordo com Bellotto (2006), essas três idades compreendem o ciclo vital dos documentos. A primeira idade é a dos arquivos correntes que abrigam 
documentos funcionais, administrativos e jurídicos, utilizados em razão dos motivos pelos quais foram criados. A segunda idade corresponde aos arquivos intermediários em que os documentos, embora já tenham ultrapassado seus prazos de validade jurídico-administrativa, ainda podem ser utilizados pelo produtor. Os de terceira idade são os permanentes que, ultrapassando o uso primário tem valor secundário, ou seja, científico, social e cultural.

Esta metodologia dinâmica de ciclo documental foi determinada pelas necessidades administrativas e sociais, acompanhadas por evolução de estudos, métodos e técnicas arquivísticas, basicamente com relação a produção, organização, armazenamento, recuperação, disponibilização e preservação documental permitindo que [...] usuários, historiadores e administradores, articulassem de forma sistêmica, o processo de busca e recuperação e assim fizessem um uso muito mais social da informação" (GALINDO, 2005, p. 6).

Embora a concepção do ciclo documental seja admitida em fases a arquivística atual aponta para a gestão integrada e sincrônica dos documentos de valor primário (corrente e intermediário) e os de valor secundário (permanente):

\footnotetext{
Não existe uma função documental administrativa e outra histórica, ambas são caras de uma mesma moeda, ou seja, a gestão dos documentos administrativos e a conservação dos históricos não devem ser consideradas duas especialidades distintas, mas sim complementares (CRUZ MUNDET, 1996; HEREDIA HERRERA, 1998 apud MORENO, 2008).
}

Conforme Rousseau e Couture (1998, apud MORENO, 2008), na gestão documental integrada, a gestão é dividida em fases de intervenção, a primeira "[...] visa à criação, à difusão e o acesso à informação orgânica", visto que "a informação deve ser concebida de forma estruturada e inteligível na forma legalmente aceita" (MORENO, 2008, p. 85). A segunda fase se refere à classificação e recuperação visando o acesso e na terceira e última fase o foco da gestão está centrado na proteção e conservação das informações.

$\mathrm{Na}$ GD, o gestor da informação deve desenvolver as ações de organização, armazenamento, representação, recuperação, disponibilização e avaliação dos documentos arquivísticos em qualquer tipo de suporte.

O processo de avaliação é fundamental para a identificação dos documentos de valor secundário para a guarda permanente. Não se pode prever a sua utilização 
de uma forma concreta em um futuro próximo ou distante, porém com a ausência do gerenciamento das informações é possível prever a perda da memória registrada.

$\mathrm{Na}$ avaliação arquivística não se analisa o documento de forma isolada, a organicidade e a contextualidade são observadas, pois "o conjunto orgânico é o objeto da função de avaliação documental" (CUNHA; OLIVEIRA; LIMA, 2015, p. 213).

Alguns dispositivos normativos regulam a gestão de documentos no Brasil. $A$ Lei 8.159 de 8 de janeiro de 1991, dispõe sobre a política nacional de arquivos públicos e privados. No artigo 3 desta lei considera-se a gestão de documentos como "o conjunto de procedimentos e operações técnicas referentes à sua produção, tramitação, uso, avaliação e arquivamento em fase corrente e intermediária, visando a sua eliminação ou recolhimento para guarda permanente" (BRASIL, 1991).

A arquivística utiliza ferramentas como Tabelas de Temporalidade e Destinação (TTD) que determinam os prazos de guarda dos documentos, sua movimentação no ciclo documental e destinação final. A elaboração destas tabelas conta com as recomendações do Conselho Nacional de Arquivos (CONARQ) e devem estar relacionadas a estrutura organizacional da instituição no tocante as suas atividades meio e fim.

Para a realização da atividade de avaliação devem ser instituídas Comissões Permanentes de Avaliação Documental (CPAD) formada por representantes da instituição e especialistas.

Com relação à implantação da CPAD em unidades que prestam assistência médica, o Conselho Federal de Medicina (CFM), no artigo 3 da resolução no 1639 torna obrigatória a criação das Comissões de Revisão de Prontuários para a avaliação permanente dos prontuários.

O CONARQ, através da Portaria no 93 de 18 de novembro de 2010, altera o nome da Câmara Setorial Sobre Arquivos Médicos para Câmara Setorial de Arquivos de Instituições de Saúde, criada pela Portaria no 70 de 16 de novembro de 2002 com a finalidade de realizar estudos e propor normas e diretrizes com relação à organização, guarda, preservação, destinação e acesso de documentos de arquivos hospitalares.

A resolução no 40, de 9 de dezembro de 2014 do CONARQ, dispõe sobre os procedimentos para a eliminação de documentos no âmbito dos órgãos e entidades integrantes do Sistema Nacional de Arquivos - SINAR. Através desta resolução fica resolvido que a eliminação dos documentos ocorrerá depois de concluído o processo 
de avaliação e seleção pelas respectivas Comissões Permanentes de Avaliação de Documentos.

A Resolução 1639/2002 do CFM "aprova as normas técnicas para o uso de sistemas informatizados para a guarda e manuseio do 'prontuário médico' e dispõe sobre a guarda dos mesmos além de estabelecer critérios para a certificação dos sistemas de informação e dá outras providências" (CONSELHO FEDERAL DE MEDICINA, 2002). Em seu artigo $2^{\circ}$ regula a guarda permanente para os prontuários dos pacientes (PP) arquivados em meio óptico ou magnético e microfilmados; e no artigo $4^{\circ}$ define o prazo de 20 anos, a partir do último registro, para a preservação de prontuários em suporte de papel (CRUZ, 2015).

Nos dispositivos normativos do artigo 4ํㅜㄹ dessa resolução e do parágrafo 3ํ do artigo 8으 da Lei dos Arquivos, Cruz (2015) observa um tratamento diferenciado para a mesma tipologia documental, porém em suporte diferente:

No artigo 4으, a Comissão Permanente de Prontuários tem a missão de elaborar e aplicar critérios de amostragem para a preservação definitiva dos documentos em papel que apresentem informações relevantes do ponto de vista médico-cientifico, histórico e social considerando o valor secundário do PP. No parágrafo $3^{\circ}$ do artigo $8^{\circ}$ da Lei dos Arquivos 2 são considerados permanentes os conjuntos de documentos de valor histórico, probatório e informativo devendo estes ser preservados em definitivo.

Esse autor observa conflito normativo entre a resolução 1639/2002 do CFM ao qual declara que os dados compostos no prontuário pertencem ao paciente e devem estar permanentemente disponíveis. Isto porque

[..] mesmo que o PP em suporte papel tenha seus dados migrados para um suporte digital ou eletrônico, antes de ser eliminado, isto não garante a disponibilidade permanente da informação, na verdade a deixa mais vulnerável a possíveis interferências e suscetível a perda. (CRUZ, 2015, p. 116).

Estas são algumas questões desafiadoras para a GD nos arquivos hospitalares. Na atividade de avaliação dos documentos, na migração para a classificação como de valor secundário, o gestor deve determinar o que irá descartar e o que será mantido e preservado. De acordo com Cloonan (2016, p. 111), o gestor deve analisar questões como:

[...] qual é o público do material, quem é /são o(s) criador(es) dos documentos, a natureza da instituição que abriga os documentos, quais materiais precisam definitivamente ser preservados por tempo indeterminado e quais devem ser 
mantidos por um período específico e até os custos e espaço para a retenção de acervos. Essas e outras questões influenciam o trabalho de avaliação. $\mathrm{Na}$ essência de tudo - a base e as orientações para a decisão dos avaliadores encontra-se o conceito de valor "permanente".

Como observado por Moreno (2008), além da recuperação rápida dos documentos de natureza arquivística, uma política de GD "impede a destruição de documentos de valor secundário, permite a diminuição da massa documental e do espaço físico para armazenagem dos documentos arquivísticos e redução de custos".

Uma política de GD que contemple a organização dos documentos em suas diferentes idades e funções deve contemplar subpolíticas como política de acesso e política de preservação.

\section{PRESERVAÇÃO ARQUIVÍSTICA DA MEMÓRIA NA SAÚDE}

A busca por fontes de informação arquivística contribuiu para a sistematização da organização e preservação dos arquivos permanentes. "Criada a demanda os administradores se obrigaram a encontrar os recursos necessários à boa prática de preservação" (GALINDO, 2005, p. 6), pois "para preservar os acervos arquivísticos é necessário organizá-los e conservá-los para servir de referência, de informação, prova, testemunho e fonte de pesquisa" (TOUTAIN, 2012, p. 18).

Para o acervo dos arquivos permanentes, a gestão e as medidas que objetivam manter a estabilidade física dos documentos compreendem processos intrinsicamente vinculados à preservação da memória.

Preservação, restauração e conservação, "são noções que se referem às tentativas de assegurar a longevidade de monumentos, habitats, artefatos, ideias, crenças e comunicação oral, pictórica e escrita" (CLOONAN, 2016, p. 108).

Como parte integrante de uma política de GD, a política de preservação documental das informações na diversidade dos suportes de documentos arquivísticos hospitalares deve ser enfatizada com relação ao reconhecimento da importância da preservação da memória na saúde, pois "a memória é o processo e os documentos são seus produtos" (CLOONAN, 2016, p. 111).

O fundo arquivístico de um arquivo hospitalar é composto pela documentação orgânica da instituição. A preservação do conjunto documental deve considerar, além das estratégias que visam a estabilização do acervo tais como controle ambiental entre outras, o respeito a proveniência e ordem dos fundos arquivísticos. 
Conhecer e compreender o potencial informacional relacionado ao bem cultural e social das informações sobre a memória da saúde, para o resgate e compreensão da identidade social de uma comunidade e para as pesquisas científicas são fatores determinantes para sua preservação.

Neste contexto, destaca-se o despertar da consciência frente à responsabilidade social dos gestores e profissionais que atuam em arquivos hospitalares, assim como dos profissionais diretamente contemplados com as ações de preservação da memória, os pesquisadores e a sociedade em geral com vistas à preservação da memória social na saúde.

\section{CONSIDERAÇÕES FINAIS}

As organizações produzem sua própria memória institucional e a memória social. O direito à memória e identidade de uma sociedade, o direito de saber, entender e contar a sua própria história é mediado pelas instituições de memória.

Desta forma, nos arquivos hospitalares a GD tem papel fundamental na avaliação, destinação, organização, preservação e disponibilização do acervo da memória da saúde com potencial informativo de interesse científico, histórico e social pela revelação da evolução das práticas, políticas e avanços em assistência na saúde, além de elementos de identidade cultural.

Frente ao exposto, os documentos dos arquivos hospitalares precisam ser avaliados e preservados de forma criteriosa e eficiente para a disponibilização e disseminação de suas informações.

O responsável pelo arquivo é o mediador entre o documento e os usuários. Os historiadores, entre o documento e seu conteúdo. Independente da interpretação do historiador, o ponto de partida é a encontrabilidade do documento que foi preservado.

Esta constatação confirma a relevância da atuação de profissionais capacitados em arquivos hospitalares e a responsabilidade social na GD. Isso, com um olhar no presente e outro no futuro, compreendendo em suas ações de gestão a importância da consideração do valor dos documentos em cada fase e a necessidade de adoção de medidas eficientes no tocante à preservação da memória social da saúde. 


\section{REFERÊNCIAS}

BARRETO, Ângela Maria. Memória e Sociedade Contemporânea: apontando tendências. Abc, Santa Catarina, Florianópolis, v. 2, n. 12, p.161-176, 10 dez. 2007.Disponível em: <file:///C:/Users/Usu\%C3\%A1rio/Downloads/506-2215-1PB\%20(1).pdf.>. Acesso em: 17 fev. 2017.

BELLOTO, Heloisa Liberalli. Arquivos Permanentes: tratamento documental. 4. ed. Rio De Janeiro: Fgv, 2006.

BRASIL, Ministério da Saúde. Secretaria de Atenção à Saúde. Departamento de Regulação, Avaliação e Controle. Manual do Cadastro Nacional dos Estabelecimentos de Saúde/ CNES - Versão 2-Atualização. Disponível em: https://www.jundiai.sp.gov.br/saude/wp-content/uploads/sites/17/2014/09/Manual-dePreenchimento-SCNES-Fichas-completas.pdf. Acesso em: 12 mar. 2017.

BRASIL, República Federativa do. Lei 8.159 de 8 de janeiro de 1991. Dispõe sobre a política nacional de arquivos públicos e privados e dá outras providências. Disponível em: <http://www.planalto.gov.br/ccivil_03/leis/L8159.htm>. Acesso em: 16 mar. 2017.

BRASIL. Rosane de Mendonça Gomes. Ministério da Saúde (Org.). Manual do Cadastro Nacional dos Estabelecimentos de Saúde/CNES. 2. ed. Brasília: Ministério da Saúde, 2006. 162 p. (Normas e Manuais Técnicos).

CLOONAN, Michèle V. Preservando documentos de valor permanente. In: EASTWOOD, Terry; MACNEIL, Heather (Org.). Correntes atuais do pensamento arquivístico. Belo Horizonte: Editora UFMG, 2016. p. 205-235.

CRUZ, Jorge Alberto. INFORMAÇÕES EM SAÚDE: um estudo da legislação brasileira. Ponto de Acesso, Salvador, v. 9, n. 1, p.111-121, abr. 2015. Disponível em: < file:///C:/Users/Usu\%C3\%A1rio/Downloads/11353-43142-1-PB.pdf>. Acesso em: 6 mar. 2017.

CONSELHO NACIONAL DE ARQUIVOS. Resolução 22/2005. Dispõe sobre as diretrizes para a avaliação de documentos em instituições de saúde. Disponível em: http://www.conarq.arquivonacional.gov.br/legislacao/resolucoes-do-conarq/264resolucao-n-22,-de-30-de-junho-de-2005.html. Acesso em: 07 mar. 2017

CONSELHO NACIONAL DE ARQUIVOS. Resolução no 40, de 9 de dezembro de 2014. Dispõe sobre os procedimentos para a eliminação de documentos no âmbito dos órgãos e entidades integrantes do Sistema Nacional de Arquivos - SINAR. Disponível em: http://www.conarq.arquivonacional.gov.br/legislacao/resolucoes-doconarq/282-resolucao-n-40,-de-9-de-dezembro-de-2014.html. Acesso em 8 mar. 2017.

CONSELHO NACIONAL DE ARQUIVOS. Portaria no 93, de 18 de novembro de 2010. Altera o nome da Câmara Setorial de Arquivos Médicos, criada pela Portaria no70, de 16 de dezembro de 2002 para Câmara Setorial de Arquivos de Instituições de Saúde. Disponível em: http://www.conarq.arquivonacional.gov.br/camarassetoriais/csais.html. Acesso em: 8 mar. 2017. 
CONSELHO FEDERAL DE MEDICINA. Resolução 1638/2002. Define prontuário médico e torna obrigatória a criação da Comissão de Revisão de Prontuários nas instituições de saúde. Brasília: Diário Oficial da União, 2002. Disponível em: http://www.portalmedico.org.br/resolucoes/cfm/2002/1638_2002.htm. Acesso em: 07 mar. 2017.

CONSELHO FEDERAL DE MEDICINA. Resolução 1639/2002. Aprova as normas técnicas para o Uso de Sistemas Informatizados pra a Guarda e manuseio do prontuário médico, dispõe sobre tempo de guarda dos prontuários, estabelece critérios para certificação dos sistemas de informação e dá outras providências. Brasília: Diário Oficial da União, 2002. Disponível em: http://www.portalmedico.org.br/resolucoes/cfm/2002/1639_2002.htm. Acesso em: 7 mar. 2017.

CUNHA, Francisco José Aragão Pedroza; OLIVEIRA, Louise Anunciação Fonseca de; LIMA, Gillian Leandro de Queiroga. A função de avaliação na gestão documental em hospitais. Acervo, Rio de Janeiro, v. 28, n. 2, p. 206-225, jul./dez. 2015 - p. 207. Disponível em:

<http://revista.arquivonacional.gov.br/index.php/revistaacervo/article/view/633/670.>. Acesso em: 20 fev. 2017.

GALINDO, Marcos. Tragédia da memória. Massangana, Recife, v. 2, n.1, p. 57-62, 2005. Disponível em:

<http://repositorio.ufpe.br/handle/123456789/13885?show=full.>. Acesso em: 10 jan. 2017.

MORENO, Nádia Aparecida. Gestão Documental ou Gestão de Arquivos. In: BARTALO, Linete; MORENO, Nádina Aparecida (Org.). Gestão em Arquivologia: abordagens Múltiplas. Londrina: Eduel, 2008. Cap. 3, p. 71-87.

PAES, Marilena Leite. Arquivo: teoria e prática. Rio de Janeiro: FGV, 2004.

SCHELLENBERG, T. R. Arquivos Modernos: princípios e técnicas. 6. ed. Rio de Janeiro: FGV, 2006.

TOUTAIN, Lídia Maria Brandão. Registro da memória social e institucional no lançamento da pedra fundamental do ICI -UFBA. In: SILVA, Rubens Ribeiro Gonçalves da. (Org.) Preservação documental: uma mensagem para o futuro. Salvador: EDUFBA, 2012, p. 15-22.

AGRADECIMENTOS: Esta pesquisa contou com as orientações da Professora Doutora Margarida Dias de Oliveira, diretora do Departamento de História da UFRN, que ministrou a disciplina: Arquivos, memória e patrimônio no curso de especialização, a quem agradeço pelo acompanhamento, sugestões e leituras críticas valorosas para a realização desse estudo. 